\section{ensaio \\ pesQuisa em educação em ciências}

\title{
A FORMAÇÃO DE PROFESSORES EM EDUCAÇÃO
} AMBIENTAL: REFLEXÕES A PARTIR DA ANÁLISE INTEGRATIVA DE PUBLICAÇÕES CIENTÍFICAS EM LIINGUA INGLESA

Rodrigo Müller Marques ${ }^{1}$

https://orcid.org/0000-0002-9611-5296

\author{
Jane Márcia Mazzarino \\ https://orcid.org/0000-0002-6051-5116
}

\section{RESUMO:}

O artigo problematiza o panorama da formação de professores em educação ambiental, seus desafios e suas potências. Tem-se por objetivo mapear, analisar e discutir a produção acadêmica publicada entre 1992 e 2017, referente à formação de professores em educação ambiental em língua inglesa a partir da Análise Integrativa. A metodologia caracteriza-se como quanti-qualitativa, bibliográfica e documental. Analisaram-se publicaçóes em língua inglesa no Portal de Periódicos da Capes. Os resultados da análise integrativa apontam dificuldades e potências. Como dificuldades identificaram-se abordagens superficiais, visão disciplinar, falta de diálogo e de motivação, rigidez de pensamento e falta de contato dos professores com a natureza. As potências encontradas foram exploração de novas metodologias, uso de tecnologias sociais e de mídia, ampliação de espaços de atividade, diversificação de abordagens, autoformação, cooperação, atividades que exploram a afetividade, a criatividade e a arte.

\section{LA FORMACIÓN DOCENTE EN EDUCACIÓN AMBIENTAL: REFLEXIONES A PARTIR DEL ANÁLISIS INTEGRATIVO DE PUBLICACIONES CIENTÍFICAS EN LENGUA INGLESA}

\section{RESUMEN:}

El artículo analiza el panorama de la formación docente en educación ambiental, sus desafíos y potencialidades. El objetivo es mapear, analizar y discutir la producción académica publicada entre 1992 y 2017, en cuanto a la formación de docentes en educación ambiental en inglés desde el Análisis Integrativo. La metodología se caracteriza por ser cuantitativo-cualitativa, bibliográfica y documental. Se analizaron las publicaciones en inglés en el Portal de Revistas Capes. Los resultados mostraron dificultades y potencias. Las dificultades halladas fueron enfoques superficiales, visión disciplinaria, falta de diálogo y motivación, rigidez de pensamiento y la falta de contacto de los profesores con la naturaleza. Las potencias encontradas fueron exploración de nuevas metodologías, uso de tecnologías sociales y de los medios, expansión de espacios de actividad, diversificación de enfoques, autoformación, cooperación, actividades que exploran la afectividad, la creatividad y el arte.

\section{Palavra-chave:}

Formação de Professores; Educação Ambiental; Portal de Periódicos da Capes; Produção Acadêmica; Análise Integrativa .

Palabras clave: Formación Docente; Educación Ambiental; Portal de Periódicos da Capes; Producción Académica; Análisis Integrativo. 


\title{
TEACHER TRAINING IN ENVIRONMENTAL EDUCATION: REFLECTIONS FROM THE INTEGRATIVE ANALYSIS OF SCIENTIFIC PUBLICATIONS IN ENGLISH LANGUAGE
}

\begin{abstract}
:
The article discusses the panorama of teacher training in environmental education, its challenges and potential. The aim is to map, analyze and discuss the academic production published between 1992 and 2017, regarding the training of teachers in environmental education in English from the Integrative Analysis. The methodology is characterized as quantitative-qualitative, bibliographical and documentary. Publications in English on the Capes Journal Portal were analyzed. The results showed difficulties and potencies. The difficulties were superficial approaches, disciplinary vision, lack of dialogue and motivation, rigidity of thought and teachers' lack of contact with nature. The potencies found were exploration of new methodologies, use of social and media Technologies, expansion of activity spaces, diversification of approaches, self-training, cooperation, activities that explore affection, creativity and art.
\end{abstract}

\author{
Keywords: \\ Teacher Training; \\ Environmental \\ Education; Portal de \\ Periódicos da Capes; \\ Academic Production; \\ Integrative Analysis .
}

\section{INTRODUÇÃO'}

A contemporaneidade traz em seu bojo um cenário de complexas problemáticas, dentre elas a ambiental, que vem despertando a atenção de governos e da sociedade em contextos locais e globalmente. Pode-se dizer que estamos passando por uma crise ambiental que a humanidade e o modelo socioeconômico vigente criaram e continuam a potencializar. A objetificação da natureza, a racionalidade econômica, os tecnicismos e a fragmentação dos saberes são apontados como causas de tal crise, que envolve os diferentes ecossistemas e o planeta como um todo (DIAMOND, 2012; PORTO-GONÇALVES, 2012; LEFF, 2006; MORIN, 2014).

Tendo em vista a problemática posta, muitas são as propostas para superá-la. Uma delas éa Educação Ambiental (EA), que é vista como uma possibilidade a ser explorada, a fim de auxiliar na resolução do que se passou a denominar como uma crise da civilização (GRÜN, 1996; CASCINO, 2003). A EA pode ocorrer em diversos espaços e de diferentes maneiras, e muitos podem ser os agentes a serem envolvidos. No caso dessa pesquisa, atenta-se para os professores, que têm papel fundamental para que ela ocorra nos diferentes espaços escolares e/ ou fora deles (TRISTÃO, 2004). Tal característica ocorre devido a “[...] uma forte tendência em reconhecer o processo educativo como uma possibilidade de provocar mudanças e alterar o atual quadro de degradação do ambiente com o qual deparamos (CARVALHO, 2000, p. 56). Sendo os docentes potenciais agentes da educação para o meio ambiente, questiona-se como está a formação de professores em educação ambiental?

Tristão (2004) situa a EA no contexto docente com alguns “nós a serem desatados”, pois muitas vezes ela é compreendida como tarefa a ser realizada pela área das Ciências ou da biologia, porém a EA "[...] não se situa e não se define por nenhum campo específico das ciências naturais, das ciências sociais ou humanas, mas sim na confluência destes [...]” (p. 97)

Embora seja essencial o trabalho com EA na área das Ciências, é preciso romper com a visão reducionista e com a rigidez epistemológica, a fim de ampliar horizontes (TRISTÃO, 2004).

Segundo Carvalho (2000), além de ser interdisciplinar, não existem fórmulas prontas e mágicas para abordar a temática ambiental. Refletir sobre caminhos já traçados, buscando aproximaçôes com diferentes saberes e áreas de conhecimento é potente, pois somente a partir de "[...] diferentes possibilidades de avaliações sistemáticas e inovações criativas, que novas perspectivas poderão ser traçadas” (CARVALHO, 2000, p. 58). 
O professor, enquanto educador ambiental, pode trabalhar através da integração entre o ser humano e o ambiente, entendendo-os como agentes da constituição do mundo, transformando valores e atitudes por meio de relações estéticas, éticas e críticas, transitando assim por diferentes saberes e áreas. Neste sentido, novas relações podem ser tecidas, sem ignorar o que vem sendo feito, reapropriando-se do já traçado para construir novas rotas para a EA (CARVALHO, 2012; GUIMARÃES, 1995).

Segundo Carvalho (2012), a EA pode partir da formação de um sujeito ecológico, o qual leva em conta os modos de ser e viver calcados em valores ecológicos que visam o equilíbrio ecossistêmico. Dessa forma, tal sujeito possui atitudes que buscam respeitar e reconhecer os diferentes seres presentes no meio em que se habita. O professor, enquanto possível sujeito ecológico, pode estar atento ao cultivo de ideias e sensibilidades em suas práticas educativas, potencializando, assim, a pluralidade da EA (CARVALHO, 2012). Há uma ressalva a ser feita, pois para que isso se efetive, é necessário que a formação de professores, inicial ou continuada, seja perpassada pela temática da EA.

Carvalho (2000) afirma que, no processo de formação de professores, é na articulação entre órgãos governamentais e não governamentais, em seus diferentes níveis, que a complexidade da educação ambiental pode ser considerada e trabalhada de forma mais adequada. Currículo, açôes interdisciplinares, uso de diferentes espaços e adequaçôes a cada ambiente e suas características são desafios a serem superados, visto que, segundo Tristão (2004), possuímos grandes déficits na formação inicial e continuada de professores em educação ambiental no Brasil. Tal hipótese foi levantada pela autora com base em seus estudos em nosso país, o que levou a situar o questionamento sobre como se está formando professores em educação ambiental em outros países? Quais são seus desafios e suas potências?

Tendo em vista a necessidade de conhecer avanços e barreiras existentes na formação de professores em educação ambiental, a fim de avaliar terrenos férteis ou áridos para se mover, toma-se como objetivo mapear, analisar e discutir a produção acadêmica publicada desde 1992 até o ano de 2017, disponível no Portal de Periódicos da Capes, através da Análise Integrativa, a qual busca construir um escopo científico a partir da sistematização de pesquisas científicas já publicadas (MENDES, SILVEIRA, GALVÃO, 2008). O estudo das publicações em inglês justifica-se por ser a língua hegemônica de produçôes do campo científico.

O objetivo do artigo e a análise integrativa desafiam-nos a transitar por produçóes acadêmicas variadas, sendo assim, optou-se por fazer uso de diferentes autores e escolas de pensamento, visando dar conta da complexidade da temática ambiental e dos diferentes caminhos que ela pode seguir. A diversidade teórica expõe, em si mesma, a potência de análises amplas de pontos que confluem ou que se afastam no campo da formação de professores em EA.

\section{METODOLOGIA}

A metodologia aplicada na pesquisa é quanti-qualitativa, bibliográfica e documental. A pesquisa bibliográfica forneceu os elementos para introdução do assunto e para o cruzamento dos dados emergentes da pesquisa documental, enquanto essa foi exercitada através da leitura dos resumos e/ou dos artigos completos obtidos através da Análise Integrativa (GIL, 2010; SEVERINO, 2007; GONZAGA, 2006; MENDES, SILVEIRA, GALVÃO, 2008).

Segundo Mendes, Silveira e Galvão (2008), a Análise Integrativa busca, na publicação de pesquisas relevantes, "[...] a síntese do estado do conhecimento de um determinado assunto [...]” (p.758). Desta forma, é possível se obter conclusóes gerais a respeito de uma área de estudo através de critérios de inclusão e exclusão previamente estabelecidos e da coleta e análise dos dados obtidos, possibilitando assim a construção de conhecimentos amplos sobre determinada temática. Tal método demonstra-se potente para esta pesquisa ao reduzir obstáculos da utilização do conhecimento científico, tornando-o mais acessível e agilizando sua divulgação (MENDES, SILVEIRA, GALVÃO, 2008). 
A partir do objetivo do estudo, a análise integrativa busca por uma amostragem, sobre a qual faz uma análise e categorização, a fim de filtrar os resultados que passarão para a etapa seguinte, de análise crítica, quando se analisam completamente os artigos para, por fim, apresentarem-se os resultados (HOPIA, LATVALA, LIIMATAINEN, 2016; WHITTEMORE, KNAF, 2005)

A coleta de dados para a composição da amostragem da Análise Integrativa partiu da busca no Portal de Periódicos da Capes, de publicações científicas em Língua Inglesa sobre Formação de Professores em Educação Ambiental, tendo como recorte temporal o período entre 1992 e 2017. Tais “recortes” se deram pelo fato do Portal conter mais de 37.000 títulos de revistas acadêmicas (periódicos) e 126 bases de dados. O período de coleta foi definido pelo tema da EA ter sido mais fortemente deflagrado a partir da Conferência das Naçôes Unidas sobre o Meio Ambiente e Desenvolvimento Sustentável, em julho de 1992 no Rio de Janeiro (Eco-92) (GRÜN, 1996).

Como referido, optou-se pelo recorte entre publicações em inglês pelo caráter hegemônico que assume na produção acadêmica. Os termos-chave utilizados para a pesquisa no Portal de Periódicos da Capes foram: "Environmental Education" e "Teacher Education" e, para ter maior abrangência, também se fez uso de "Environmental Education" e "Teacher Training". ${ }^{2} \mathrm{Na}$ busca, optou-se ainda por pesquisar as palavras-chave no assunto e usou-se o AND como campo de complemento, para obter resultados específicos de pesquisas que vinculassem a educação ambiental à formação de professores. Buscaram-se livros, teses e artigos.

Durante a etapa que caracteriza-se pela categorização e filtragem, alguns materiais não foram analisados pelos seguintes fatores de exclusão: não se encaixavam no tema da pesquisa, atendiam somente um dos conceitos-chave, repetiram-se durante a coleta, a publicação não era em língua inglesa. Após a "triagem”, sobraram 316 materiais, dos quais foram lidos os resumos e, quando esses não forneciam os elementos essenciais para análise, leu-se o artigo completo, o que constituiu-se como a etapa de análise crítica, quando foi se definindo a forma de apresentação dos resultados em determinadas categorias, optando-se por separar os dados quantitativos dos dados qualitativos. Dados quantitativos: Ano de publicação; Local de publicação; Técnicas de metodológicas (uso de questionários, entrevistas, diários de campo, etc.); Natureza da pesquisa; Disciplinar ou multi/interdisciplinar; Ambiente da pesquisa. Dados qualitativos: Objetivos e Resultados. As categorias de análise estão expostas no Quadro 1 e apresentam a forma de organização dos resultados da Análise Integrativa. As categorias foram definidas a priori, já os elementos que constituem as categorias, definidas como microcategorias (em parênteses) emergiram das análises.

O método de categorização seguiu o proposto por Moraes (2007), que define a possibilidade de se eleger uma forma de classificação a priori (o que já se espera encontrar na pesquisa) e outra emergente (o que surge como relevante durante o fazer científico). O processo de categorização realizou-se de maneira manual (apontamentos, anotaçôes feitas à mão e no Word®) além de tabulações para gráficos em planilha de cálculo Excel®

Quadro 1. Categorias de análise

\begin{tabular}{|l|}
\hline Ano \\
\hline Título da publicação \\
\hline Revista da publicação \\
\hline Local da publicação (país ou estado de onde a pesquisa foi originada) \\
\hline Objetivos (composições contextuais, concepções propositivas e experienciação) \\
\hline Técnicas metodológicas (questionários, entrevistas, diários de campo, etc.) \\
\hline Abordagem (quantitativa, qualitativa ou quanti-qualitativa) \\
\hline Natureza da pesquisa (exploratória, descritiva, intervenção, etc.) \\
\hline Disciplinar ou multi/interdisciplinar (possui ligações entre disciplinas) \\
\hline Ambiente da pesquisa (ar livre, escola, universidade, etc.) \\
\hline Resultados (o que emergiu da pesquisa) \\
\hline
\end{tabular}

Fonte: Dados da pesquisa. 
Ao coletar o ano da publicação, busca-se observar aumentos, recuos ou sazonalidades nas publicaçóes. Os campos referentes aos títulos e às revistas, têm caráter informativo e de complementaridade, já que facilitam o acesso posterior aos materiais que possam interessar.

A categoria Local da pesquisa mapeia as origens das pesquisas por país, visualizando preocupaçôes emergentes e possibilidades, tanto institucionais quanto pessoais em determinados Estados-Nação. As categorias Objetivos, Técnicas Metodológicas, Natureza da pesquisa e Abordagem, assim como Resultados, seguem propostas de construçốes para pesquisas científicas, devidamente baseadas nas propostas de autores como Gil (2010), Severino (2007) e Lakatos (2010), que levam tais categorias como essenciais nos fazeres científicos.

$\mathrm{Na}$ análise dos objetivos das publicaçôes, optou-se por uma abordagem a partir de três categorias: Composições contextuais; Concepçôes propositivas; Experienciação. A categoria Composiçôes contextuais foi composta com a presença de estudos exploratórios e descritivos que buscam aproximações com o contexto, mas sem necessariamente atuar ou propor uma formação em específico ou uma intervenção. Em Concepções propositivas elencam-se propostas e sugestóes para inovação, ação e formação de professores em educação ambiental. Por fim, a categoria Experienciação envereda para trabalhos voltados à descrição e análise de intervençốes realizadas em educação ambiental. Essa categorização está exposta na Figura 1, que demonstra a ligação retroalimentativa entre as três categorias.

Figura 1. Categorias da coleta

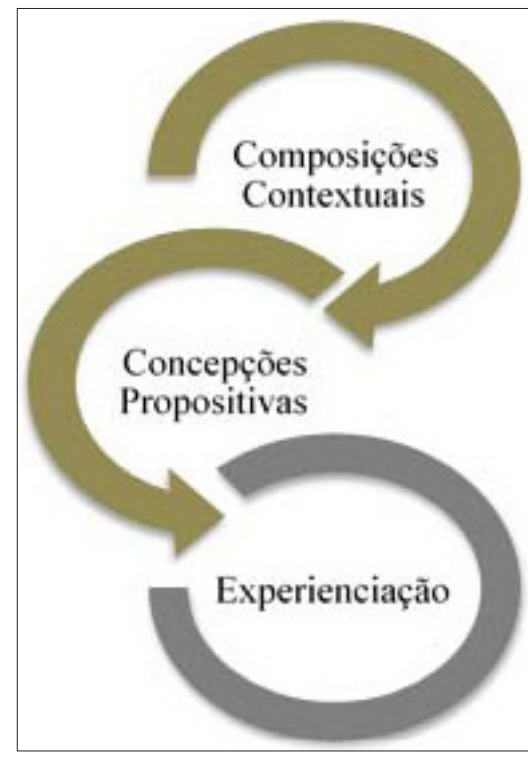

Fonte: Dados da pesquisa.

Utilizou-se a categoria "Abordagem" como termo para aquela que envolve diversos conjuntos metodológicos e referências epistemológicas distintas, que formam então, abordagens qualitativas, quantitativas e quanti-qualitativas. Na categoria Natureza da Pesquisa exploram-se as finalidades da pesquisa, ou seja, se são pesquisas exploratórias, descritivas, intervencionistas, metodológicas, etc. (GIL, 2010; SEVERINO, 2007).

No caso das categorias Ambiente da pesquisa e da Disciplinaridade ou Multi/Interdisciplinaridade”, parte-se de Leff (2000), Tristáo (2004) e Cascino (2003), ao referirem a importância de se observar onde, como e quando se faz a educação ambiental, assim como o fator multi ou inter-relacional existente entre disciplinas em suas práticas.

Em alguns casos não foi possível identificar alguns dos parâmetros, pois não se obteve acesso à publicação. Contabilizou-se as pesquisas não encontradas e não acessadas, para que seja possível um pareamento de resultados para as análises. 


\section{O QUE NOS CONTAM EM INGLÊS}

Os resultados iniciais da pesquisa em Inglês apontaram pluralidades, as quais dão "os tons” para as análises aqui tecidas. Dessa forma, inicia-se pelo número de publicações, categoria que nos fornece os "primeiros murmúrios”, os quais podem ser observados no Gráfico 1 :

Gráfico 1. Número de publicações por ano

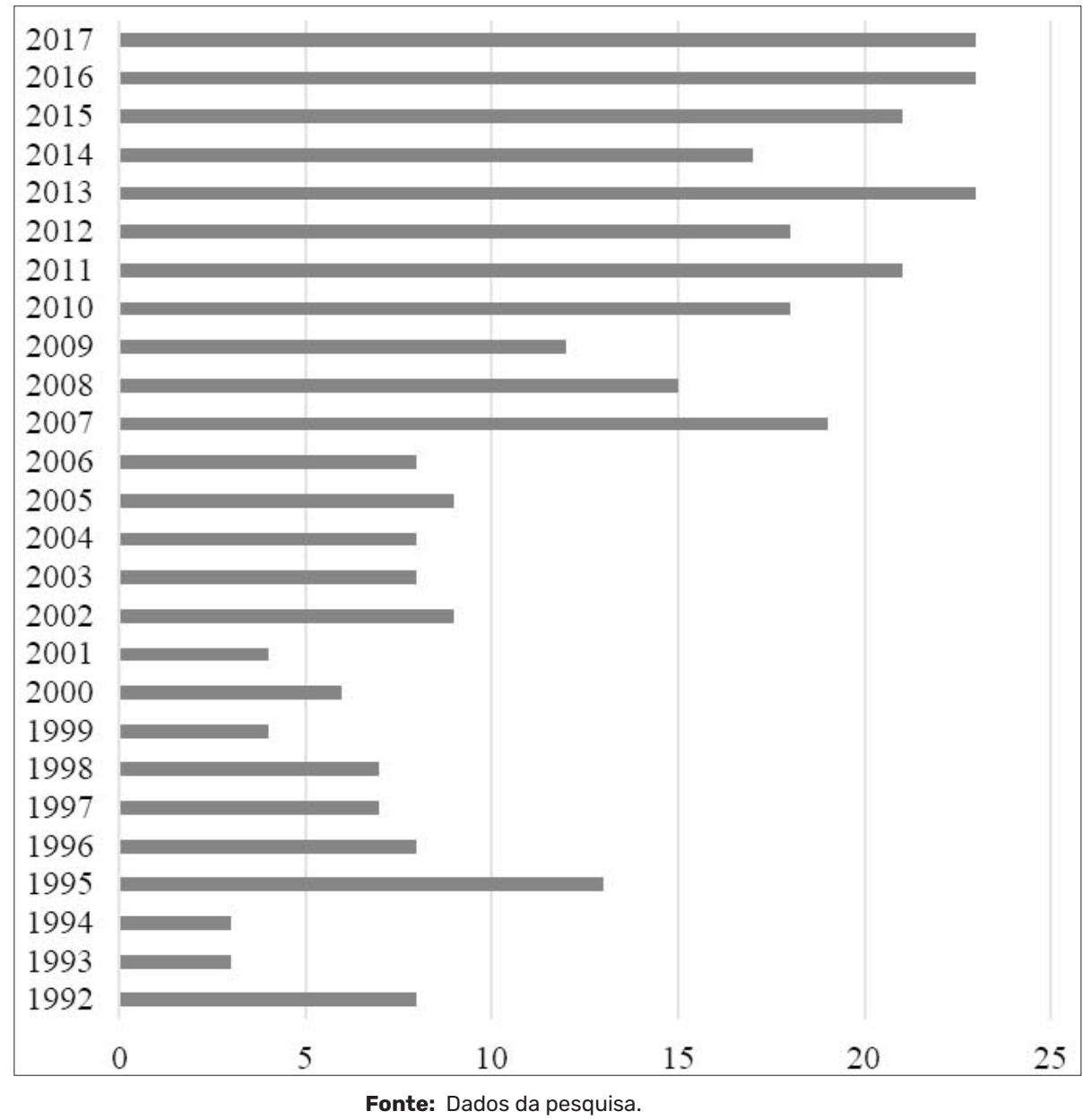

É possível notar que a partir de 2007 ocorreu um aumento do número de publicações, sempre acima de 10 publicaçôes por ano. Em 1995 também se notou um volume expressivo se comparado aos anos próximos, o que imputa sazonalidade evidente. Os anos mais recentes demonstram um maior número de publicaçóes, denotando, assim, uma crescente preocupação com o "desafio ambiental" e maior atenção para com a educação ambiental e a formação de professores (PORTO-GONÇALVES, 2012, CASCINO, 2003).

Explorar em quais países as pesquisas foram realizadas também demonstrou-se pertinente, pois assim se pode observar a pluralidade de origens dos estudos, como o Gráfico 2 apresenta: 


\section{Gráfico 2. Número de publicações por ano}

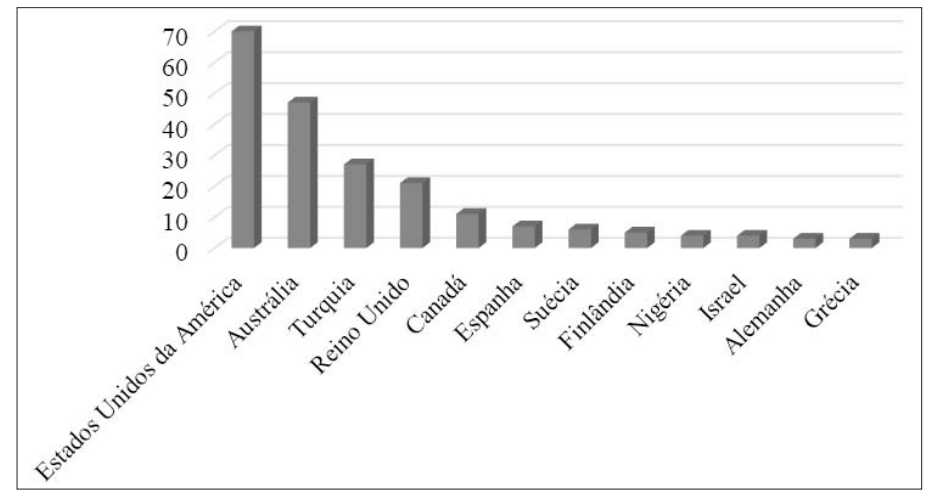

Fonte: Dados da pesquisa

Estados Unidos, Austrália, Turquia e Reino Unido se salientam como os países com maior expressividade numérica de publicações. Além dos resultados no gráfico acima, com duas pesquisas publicadas em inglês aparecem: Portugal, Bélgica, República Checa, Índia Hong Kong, Chipre, Etiópia, Zimbábue, Costa Rica, Botswana, Brasil, América Latina e África do Sul. Além desses, houve países que tiveram uma pesquisa realizada em seu território: Sérvia, Taiwan, Uganda, Jamaica, Hungria, Holanda, Noruega, África Subsaariana, Coréia do Sul, Kosovo, Singapura, Jordânia, Malásia, França, Suíça, China, Trinidad, Romênia, Zâmbia, Rússia, Dinamarca, Filipinas, Escócia e Ruanda.

Emergiram pesquisas de diversos lugares do globo, denotando novamente uma preocupação ambiental que não se restringe a um Estado-Nação ou a um continente, como sugere Porto-Gonçalves (2012). A crise ambiental e a preocupação em educar para o meio ambiente coloca toda a "civilização" num lugar de centralidade, onde as buscas por soluções a partir da educação ambiental se espraiam, envolvendo diferentes discursos e espaços de ação em busca da sustentabilidade (LEFF, 2010).

Após analisar as origens dos estudos publicados, observou-se os objetivos destas. A categorização deles encontra-se no Quadro 2:

Quadro 2. Categorias relacionadas aos objetivos das publicações

\begin{tabular}{|c|c|}
\hline CATEGORIAS & \\
\hline $\begin{array}{c}\text { Composições } \\
\text { contextuais }\end{array}$ & $\begin{array}{l}\text { - Discutir a formação inicial de professores para a educação ambiental (currículos de cursos de } \\
\text { graduação); } \\
\text { - Explorar os padrões, as definições conceituais, as emoções e os entendimentos dos } \\
\text { professores sobre a educação ambiental (EA); } \\
\text { - Analisar a bibliografia, os desafios, as competências e o panorama de professores para a EA } \\
\text { em determinado contexto; } \\
\text { - Analisar o desacordo dos currículos com as políticas públicas, seja em âmbito local, nacional } \\
\text { ou global; } \\
\text { - Descrever a visão geral do meio ambiente em escolas; } \\
\text { - Analisar o impacto da legislação sobre a "realidade" das práticas dos professores em EA; } \\
\text { - Analisar a aplicabilidade dos currículos em sua relação com as políticas públicas, assim como } \\
\text { observar e elencar tendências institucionais para com os currículos e a EA presente neles (ou não); } \\
\text { - Identificar barreiras para a Educação de professores em EA em um panorama contextual; }\end{array}$ \\
\hline
\end{tabular}




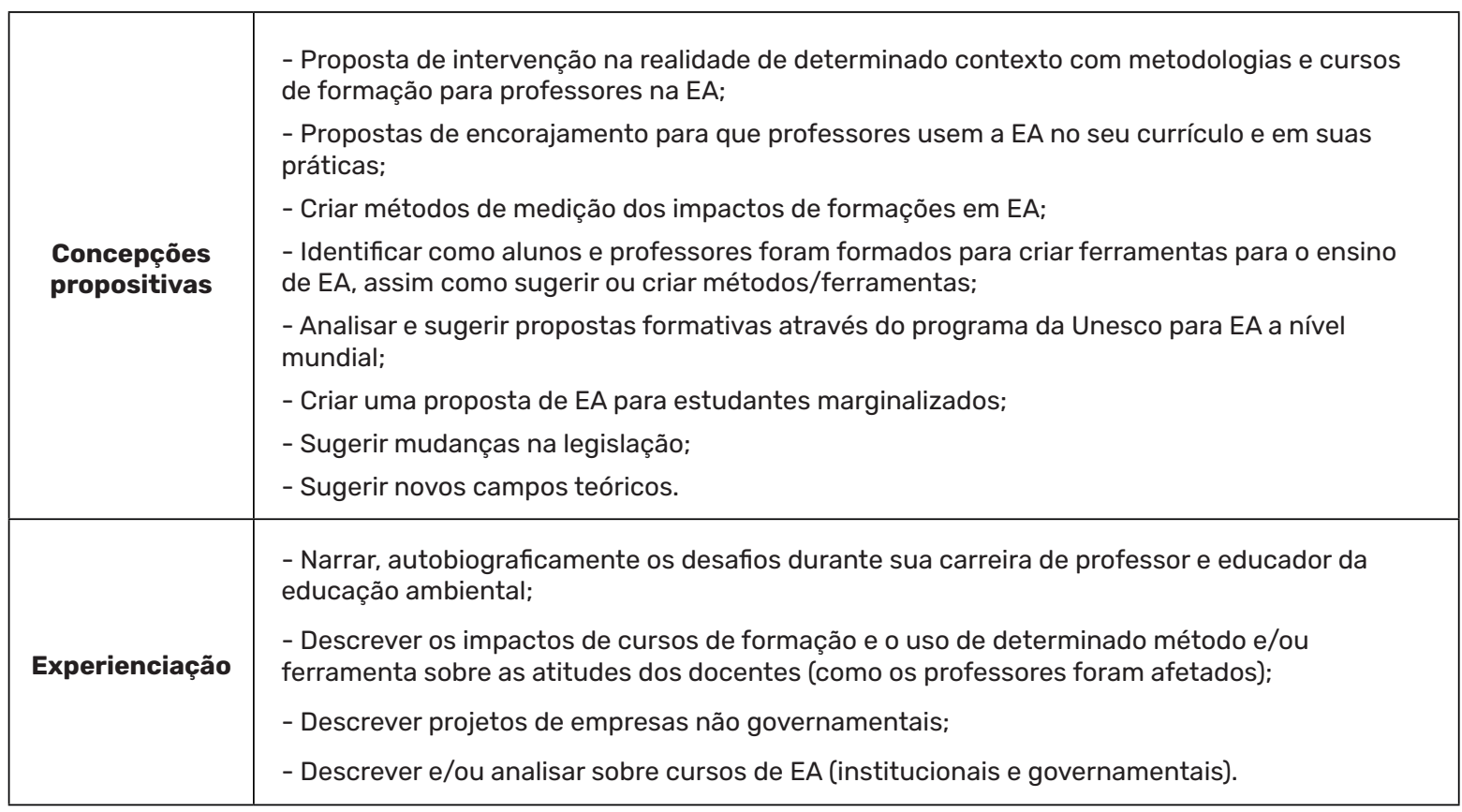

Fonte: Dados da pesquisa.

As Composições contextuais salientam a formação e a compreensão da EA e do meio ambiente, assim como atitudes e avanços identificados pelos autores dos estudos. Observa-se também que a triangulação entre leis e diretrizes e os currículos têm despertado interesse dos pesquisadores que publicam em inglês. A categoria Concepções propositivas têm como tônica a sugestão de métodos, propostas de intervenção, ferramentas para o ensino, mudanças legais e novos campos teóricos para a educação ambiental. Na categoria Experienciação emergiu a descrição de práticas (programas, cursos, projetos) em diferentes contextos (governamentais e não governamentais), assim como seus impactos e influências sobre os participantes.

As concepções propositivas carregam consigo o intuito de alterar a realidade, aproximando-se do que sugere Freire (2015): refletir para então agir. Criar, propor e alterar métodos sugere uma consciência de inacabamento, de traçados novos para contemplar a complexidade emergente, tanto na ciência quanto na vida, denotando necessidades de aproximações e reapropriações do saber ambiental com a educação (LEFF, 2006; MORIN, 2005; 2014). Pela diversidade de propostas, nota-se que, assim como sugere Barcelos (2008), não há uma metodologia única, mas sim, alguns caminhos e possibilidades que são traçados para a educação ambiental de modo geral.

As intervenções são uma possibilidade. Conforme sugere Carvalho (2000), propor intervenções demonstra que a EA na formação de professores ganha muito ao refletir sobre suas metodologias e epistemologias, o que faz avançar a qualificação para a ação consciente e sensível do docente. Emerge assim, o intuito de inovar, de alimentar as possibilidades que os contextos e os agentes oferecem para transformar a realidade (LEFF, 2010).

Tanto a formação de professores quanto a educação ambiental exigem processos intervencionistas na realidade. As práticas fornecem resultados que se refletem na transformação de sujeitos e realidades. A educação Ambiental, segundo Loureiro, é uma práxis educativa e social, que objetiva construir valores, conceitos, habilidades e atitudes para ação lúdica e responsável, transformando assim materialidades e subjetividades (TRISTÃO, 2004, LOUREIRO, 2002). Partindo-se desse ponto, é possível escutar vozes diferentes, que trazem timbres diversos e possibilidades múltiplas para construir narrativas, diálogos e significados distintos capazes de fazer avançar os processos formativos docentes em EA.

Na categoria "Experienciação”, notam-se pesquisas que atuam sob determinada realidade, buscando, além de intervir, também observar quais os impactos gerados pelas formações de docentes em educação am- 
biental. A tentativa de criar e usar ferramentas, denota uma busca por "esboços metodológicos" que precisam levar em conta o contexto e suas particularidades (BARCELOS, 2008; SILVA, 2000).

Trabalhar com educação ambiental significa reunir capacidades de superação dos desafios cotidianos e também esperar que quem nela atua, se posicione como construtor de processos que levem seus educandos/ aprendizes a ressignificarem suas ações no mundo. Nesse sentido, experienciar com diferentes técnicas e tecnologias é essencial para a qualificação docente e discente no que tange a educação ambiental (GOUVÊA, 2006).

Analisar e discutir a formação inicial e seus impactos contextuais são passos importantes no entendimento das condiçôes, das necessidades, dos desafios e das possibilidades para formar-se professor. Se desejamos uma ação educativa ambiental significante e significativa, faz-se necessário a compreensão do contexto e, também, a reflexão sobre o mesmo, pois com os devidos meios, o professor pode atuar científica e politicamente na construção do conhecimento ambiental, construindo com seus estudantes novos entendimentos do meio no qual se inserem (GOUVÊA, 2006; CARVALHO, 2000).

Segundo Gouvêa (2006), os problemas estruturais (má remuneração, ausência de tecnologias e pequeno reconhecimento) e institucionais se colocam como empecilhos, minando potencialidades para a formação docente nos diferentes contextos. Nesse sentido, para que a educação de modo geral e a educação ambiental de forma específica avancem, é necessário que a valorização na formação do professor seja posta em questão, pois “[...] no processo de valorização, as categorias política, técnica, profissional e humana tornam-se indissociáveis no plano profissional (GOUVÊA, 2006, p. 165).

No que tange às técnicas metodológicas, não foi possível identificá-las em 75 publicações. No restante dos casos, notou-se uma grande diversidade delas, o que denota que é preciso construir metodologias plurais para as temáticas socioambientais enfrentadas nos diferentes contextos, levando-os em conta a proposta de Barcelos (2008). O Gráfico 3 traz as diversidades metodológicas encontradas nas publicaçôes exploradas.

Gráfico 3. Técnicas metodológicas das pesquisas

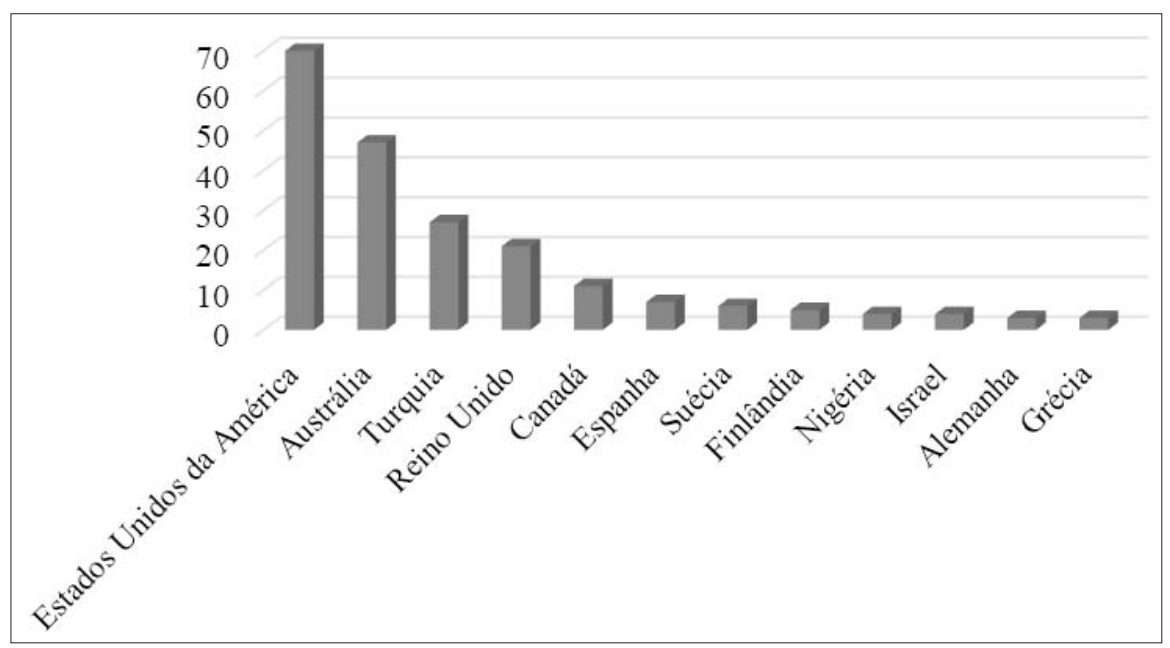

Fonte: Dados da pesquisa.

Houve uma preponderância de questionários, entrevistas e de análises documentais nos estudos. Tais técnicas possibilitam explorar determinados contextos, observando possíveis ligaçốes entre fatores de modo a se criar um panorama (GIL, 2010). A técnica de observação também é de amplo uso, demonstrando a tendência de colocar o pesquisador como sujeito e uma certa "abertura" das ciências à experiência, o que, para a formação de professores, é essencial (TARDIF, 2012).

Os diários de campo, enquanto técnica, possibilitam relembrar acontecimentos empíricos, revisitando memórias e "reanimando" fatos passados, trazendo à tona potencialidades diversas, que ocorrem, em 
geral, quando são realizadas pesquisas de caráter intervencionista ou pesquisa-ação (ECKERT, ROCHA, 2008; AGROSINO, 2009). Parece-nos coerente a correlação entre buscar intervir e refletir sobre o contexto através das possíveis técnicas metodológicas.

Além dessas técnicas, em cinco pesquisas se fez uso de fóruns na internet e de autobiografia ou autorreflexão. Em dois casos foram usados mapas conceituais produzidos pelo grupo pesquisado e, em um caso, se fez uma análise integrativa de artigos (algo semelhante a essa etapa da pesquisa, porém, de forma mais restrita). A diversidade de técnicas demonstra a amplitude de possibilidades viáveis de coleta de dados, além de muitas dela poderem ser usadas conjuntamente, seja para explorar ou intervir na realidade. Verificou-se uma preponderância de técnicas tradicionais (questionários e entrevistas), que convive com outras técnicas nas quais o pesquisador se coloca "dentro" do processo (diários de campo, observação, etc.).

Quanto à Abordagem, separou-se em quantitativa, quanti-qualitativa ou qualitativa, como o Gráfico 4 demonstra.

\section{Gráfico 4. Abordagens metodológicas das pesquisas}

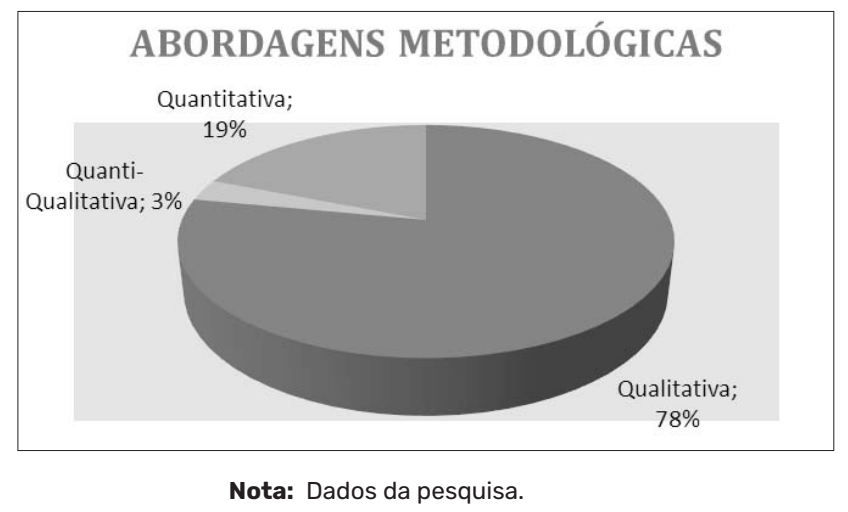

Os resultados demonstram um hibridismo de abordagens, embora exista uma preponderância da pesquisa qualitativa. As outras abordagens (quanti-qualitativa e quantitativa) são utilizadas em pesquisas no âmbito educacional e fornecem possibilidades potentes, porém, como afirma (GONZAGA, 2006), a abordagem qualitativa tende a ser mais utilizada devido a sua amplitude de técnicas e das diversas possibilidades de análise disponíveis, não se restringindo a dados "fechados", portanto estando aberta a diversas possibilidades.

$\mathrm{Na}$ categoria "Natureza da pesquisa", resolveu-se, optar por uma triagem segundo os objetivos gerais e os métodos aplicados (GIL, 2010; VERGARA, 2005), como fica claro no Gráfico 5:

\section{Gráfico 5. Natureza das pesquisas publicadas}

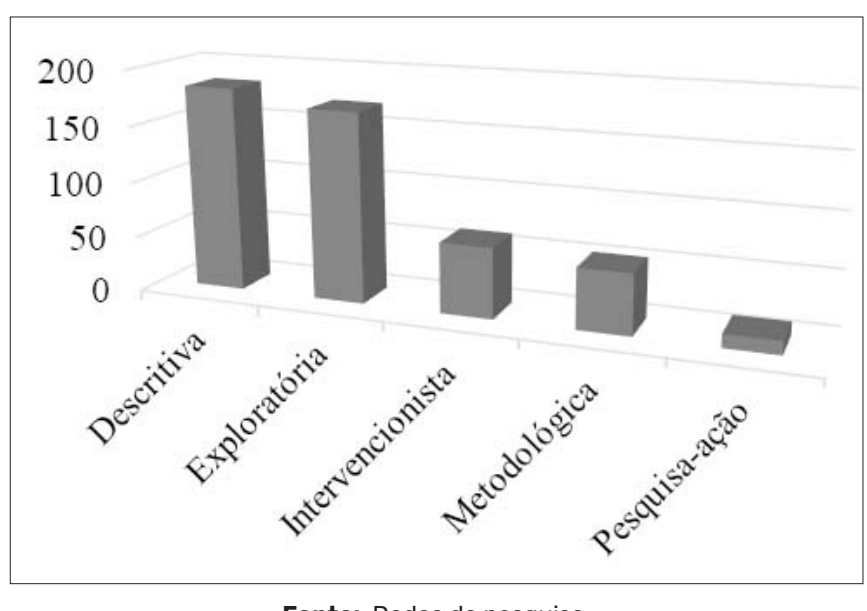

Fonte: Dados da pesquisa. 
Assim como nas técnicas de pesquisa, nessa categoria há uma clara tendência pelas opçôes tradicionais, como comprova o alto índice de estudos descritivos e exploratórios (GIL, 2010), porém, não se pode ignorar o número relevante de pesquisas intervencionistas, metodológicas e pesquisas-ação. Nesse sentido, os dados aproximam-se do que propõe Gouvêa (2006) ao afirmar que a sequência ação-reflexão-ação é essencial, ou seja, intervir, refletir e aprimorar a intervenção são passos potentes para a formação de professores em EA.

As pesquisas voltadas à experimentação e à ação colocam-se em consonância aos principais desafios da formação de professores em educação ambiental, pois a ideia de formação prática é largamente apropriada. A experiência e a transformação dos seres e do meio são elementos valorizados na educação ambiental contemporânea em diferentes vertentes (TRISTÃO, 2004).

Segundo Neuenfeldt (2017), a formação de professor precisa, além dos conhecimentos teóricos e pedagógicos, de uma formação pessoal e estética, o que se torna viável a partir do caráter experiencial de muitas pesquisas. Tais pressuposiçóes foram feitas anteriormente por Carvalho (2000), o qual expóe que "[...] tanto no caso da formação inicial como no caso da formação contínua, acredito que as palavras de ordem deveriam ser criatividade, flexibilidade e enriquecimento de experiências” (p. 60). Dessa forma, os dados obtidos demonstram que os primeiros passos foram dados, mas é importante seguir caminhando.

$\mathrm{Na}$ coleta de dados, foram envolvidas mais de uma disciplina em 254 vezes dos 316 materiais analisados. Estudos voltados somente às Ciências apareceram oito vezes, a Geografia, quatro vezes, Biologia, Geociências, Enfermagem e Artes, uma vez. Em 46 casos não foi possível identificar se o estudo foi disciplinar ou a multi/interdisciplinar.

Usou-se o termo multi/interdisciplinar para delimitar todos os estudos que trabalhavam com mais de uma "área do conhecimento" e interdisciplinar para estudos que buscaram produzir resultado comum a partir da confluência de diferentes áreas do saber, fato que envolve tempo, planejamento, ação, revisão, diálogo, reflexão e produção em conjun to (FLORIANI, 2000; LEFF, 2000; SILVA, 2000). Partindo desse panorama, notou-se que a maior parte dos trabalhos usou da multi/interdisciplinaridade, o que dialoga com os desafios da educação ambiental e da formação de professores cobram (LEFF, 2010; TRISTÃO, 2004).

Segundo Loureiro (2002), a educação ambiental ganha muito ao ser interdisciplinar, ainda mais se voltada à resolução de problemas locais, gerando processos participativos, criativos e que valorizam a ação. Sendo assim, intervir através das diferentes áreas do conhecimento pelos processos participativos é uma potência a ser exercitada.

Quanto ao ambiente da pesquisa, foi possível identificar certa diversidade de espaços utilizados, como explicitado no Gráfico 6: 


\section{- Gráfico 6. Ambientes das pesquisas publicadas}

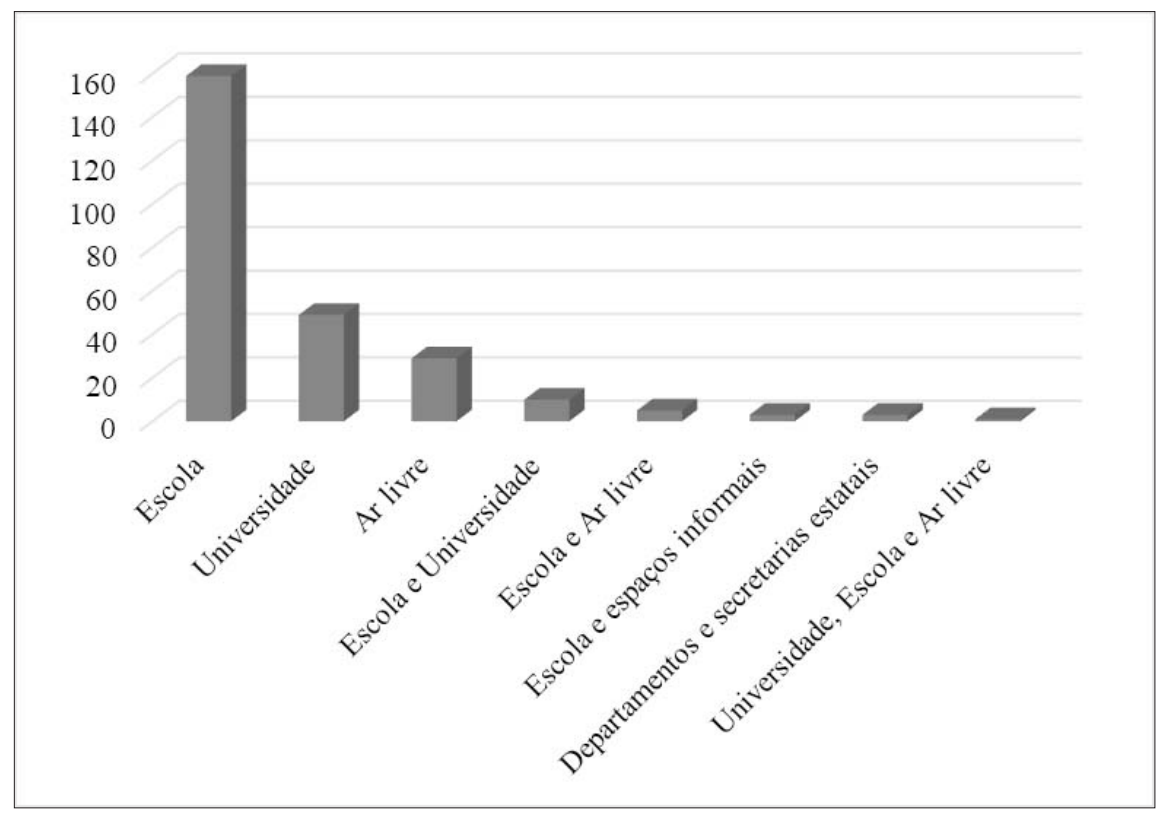

Fonte: Dados da pesquisa.

Houve uma preponderância de pesquisas realizadas em espaços escolares, enquanto pesquisas em universidades e ao ar livre não passam de 60 citaçôes nos materiais analisados. Alguns estudos vincularam escola e universidade, escola e espaços ao ar livre, além de um caso, que envolveu escola, universidade e ao ar livre. Espaços informais e institucionais do Estado também foram envolvidos em pesquisas. Em 57 casos, não foi possível identificar qual foi o espaço que a pesquisa abrangeu.

Tanto a formação de professores quanto a educação ambiental podem ocorrer em diferentes espaços, a partir de diversas tecnologias, sejam elas sociais ou midiáticas. Cada espaço e cada ação fornecem diferentes experiências, as quais podem ser exploradas a partir de práticas e vivências com interinfluências diversas e potentes, tateando assim a complexidade do mundo e do saber ambiental. A experiência de conviver amistosamente com o não humano para a ação educativa potencializa a formação de um sujeito ético, capaz de reconhecer que há uma vida não humana pulsando no ambiente e que ela tem o direito de existir e durar para além das necessidades desse sujeito, possibilitando consciência e sensibilidade (CARVALHO, 2012; CARVALHO, 2000).

A formação de professores que explora as vivências tem uma potência diferenciada. Provocar o professor a se deslocar, a colocar-se em espaços diferentes, como ao ar livre, ou seja, em contato direto com paisagens não totalmente transformadas pelo humano, pode fazer germinar outros reconhecimentos, como a dessacralização da ideia de "natureza" sagrada e colocá-lo, enquanto agente. Uma educação que explora o contato com a natureza, explora estéticas e mediações envolvendo seres e meios, que os espaços "formais" de aprendizagem, por vezes, não possibilitam (CARVALHO, 2012; TRISTÃO, 2004).

Variar os espaços para formação de professores em educação ambiental, impulsiona a transformação de modos de ver e sentir. Essas práticas provocam (re)construções éticas e estéticas no agir com o meio, meandros importantes de atuação docente (CARVALHO, 2000). Adentrar em ambientes diferentes da escola, gera novas sensibilidades e sentidos, como sugere Godoy (2007).

Nas análises dos resultados levando em conta as mesmas três categorias usadas para avaliar objetivos, foi necessário, na categoria "Composições contextuais", dividi-la em duas subcategorias: potencialidades e desafios. O intuito, ao criar tais subcategorias, é clarificar os resultados analisados, o que segundo Severino (2007) é importante para o trabalho científico, já que organiza as análises. No quadro 3 encontra-se a construção de categorias e subcategorias referentes aos resultados das pesquisas publicadas. 


\begin{tabular}{|c|c|}
\hline CATEGORIAS & \\
\hline $\begin{array}{l}\text { Composições } \\
\text { contextuais }\end{array}$ & $\begin{array}{l}\text { - Potencialidades: uso da afetividade; literatura na e para a EA; aplicação uma educação } \\
\text { holística; uso das TICs na EA para produção de conhecimento construído colaborativamente; } \\
\text { pluralidade de formação de professores e de conhecimentos adquiridos para a EA; relevância } \\
\text { na aplicação da EA em diversas áreas disciplinares; formação científica do professor, } \\
\text { potencializando assim, sua vontade de aprender e usar a EA; aspectos culturais latentes } \\
\text { na formação de professores; pensamento multi/interdisciplinar; uso da criatividade para } \\
\text { trabalhar a EA; influência positiva de educadores em seus estudantes; sustentabilidade } \\
\text { e interdisciplinaridade nos currículos, além de torná-los "mais transversais"; arte como } \\
\text { possibilidade de conscientização e como disciplina profícua para a EA; habilidades para } \\
\text { se lidar com a EA; professores com valores pró-ambientais e bem informados sobre a EA; } \\
\text { conhecimento sobre as mudanças climáticas bem elaborados. } \\
\text { - Desafios: cursos iniciais que não tratam ou tratam apenas superficialmente a EA; falta de } \\
\text { convívio ao ar livre; elitismo na aplicação da EA; ausência de trabalhos em conjunto entre } \\
\text { instituições e sociedade; "falta de desejo" por parte dos professores de aprenderem e } \\
\text { incorporarem a EA em suas práticas; aplicações frágeis e limitadas das aberturas políticas na } \\
\text { prática real da EA; necessidade de maiores reflexões por parte dos professores de sua prática } \\
\text { cotidiana; descompasso entre as mudanças de instituições educacionais (mudam lentamente) e } \\
\text { a sociedade (muda rapidamente); ausência de abordagens sistêmicas para melhorar a formação } \\
\text { de professores; escassez de políticas públicas orientadas para a formação de professores em EA; } \\
\text { visões unidisciplinares e antropocêntricas do ambiente; déficits nas abordagens de valores éticos } \\
\text { e da cidadania dentro da EA por parte dos professores; atitudes negativas e despreparo para } \\
\text { lidar com a EA; baixo nível de preocupação com questões globais; pouco conhecimento sobre o } \\
\text { currículo e a ausência de EA nos currículos; baixa qualificação docente em EA e pouca vontade } \\
\text { de participar de formações. }\end{array}$ \\
\hline $\begin{array}{l}\text { Concepções } \\
\text { propositivas }\end{array}$ & $\begin{array}{l}\text { - Criar cursos que orientem para a ecojustiça; } \\
\text { - Usar da ecopedagogia, utilizando espaços ao ar livre } \\
\text { - Fornecimento de auxílio para definição e resolução de problemas contextuais para } \\
\text { professores através de projetos; } \\
\text { - Fazer uso da sensibilidade, afetividade e reflexão para aplicar a EA; } \\
\text { - Mudar a legislação, fornecendo mais autonomia para escolas e professores; } \\
\text { - Necessidade de colaboração para a EA e para a Formação de professores; }\end{array}$ \\
\hline Experienciação & $\begin{array}{l}\text { - Proposta de modelo de curso para o ensino da EA a partir de intervenção; } \\
\text { - Uso e criação de ferramentas para medir conhecimentos e atitudes em EA por parte dos } \\
\text { professores; } \\
\text { - Análise de cursos/práticas que geraram impactos positivos, dos quais destacaram-se: } \\
\text { cooperação para inovação; participação ativa e dialógica de professores; docentes assumiram } \\
\text { papéis de líderes nas atividades; ampliação de visões sobre o desenvolvimento sustentável; } \\
\text { professores revalorizaram a EA; métodos mistos como bons aportes para a prática (ar livre, sala } \\
\text { de aula, estudos quanti-quali). } \\
\text { - Análise de cursos/práticas que geraram resultados pouco profícuos: muitos professores } \\
\text { participaram do curso, mas não por ser ele de caráter ambiental; as atitudes e conceitos dos } \\
\text { professores pouco mudaram; necessidade de mais diálogo entre professores, tanto em cursos } \\
\text { como em sala de aula; }\end{array}$ \\
\hline
\end{tabular}

Fonte: Dados da pesquisa.

Os resultados nas Composiçóes contextuais apontam para a presença da afetividade, da criatividade, da arte e das tecnologias midiáticas como possibilidade. Também logram espaço a interdisciplinaridade e a relevância dos processos de comunicação na formação de professores. A superficialidade, o despreparo, as limitaçôes, o desconhecimento, as visões disciplinares, a falta de políticas públicas de formação docente em 
educação ambiental, assim como o déficit no contato com a natureza por parte dos professores apareceram como uma construção a ser realizada.

Nesta categoria os desafios e as potencialidades emergentes reafirmam a importância de levar em consideração o contexto na formação de professores em educação ambiental, de modo a gerar reflexôes para se atuar sobre a realidade, passos essenciais a serem seguidos (GOUVÊA, 2006). As potencialidades emergentes demonstram que as abordagens podem ser múltiplas. Uma das possibilidades é usar as tecnologias de mídia para aproximar professores, alunos e sociedade, como sugere Sibilia (2012). Ela afirma que a escola precisa adaptar-se e fazer uso do aparato comunicacional disponível, no entanto, o aparato tecnológico coloca-se ainda como um desafio contemporâneo que precisa ser enfrentado, pois possui múltiplas potências, conforme sugere Carvalho (2000). O contexto da pandemia gerada pela COVID-19 acelerou o uso das tecnologias, mas seu uso no contexto da educação ambiental precisa ainda ser melhor explorado.

Anda, a necessidade de interdisciplinaridade emergiu nos resultados, porém, sem abandonar os saberes disciplinares (LEFF, 2000; FLORIANI, 2000). A EA, por ser multi/interdisciplinar, tem muito a ganhar a partir de processos que usam a criatividade, a afetividade e a arte, visto que sentir afeto para com a natureza é formar-se cidadão do mundo. No que diz respeito aos currículos, observa-se a necessidade de alterá-los, incluindo elementos da sustentabilidade e da interdisciplinaridade, tornando-os "mais transversais" e contextuais, podendo emergir construçôes flexíveis e dinâmicas, capazes de facilitar o tratamento das questôes ambientais, conforme afirma Carvalho (2000).

Portanto, a formação de professores faz emergir a pluralidade e as diferenças culturais, podendo expandir sua capacidade transformadora, além de auxiliá-los em suas relações e práticas, através da reflexão, do conhecimento e da afetividade (MORIN, 2003; IMBERNÓN, 2006; MATURANA, 1998).

As concepções dos professores aparecem tanto como potencialidade, quanto como desafio, visto que, em alguns casos, demonstraram serem sujeitos “esclarecidos” no que se refere à educação ambiental, enquanto em outros há déficits visíveis quanto ao conhecimento e engajamento. De qualquer forma, é preciso partir do que o professor sabe para buscar uma formação mais complexa, que também desenvolva habilidades e atitudes para o "enfrentamento" das problemáticas socioambientais (CARVALHO, 2012).

A formação inicial, ao não tratar amplamente a educação ambiental, assim como a não sistematização da EA nos currículos de formação docente, atravancam possíveis avanços no trabalho qualificado de professores em seus contextos locais. Dessa forma, conforme coloca Carvalho (2000), é pertinente que o Estado e outras instituições civis sejam capazes de oferecer serviços e possibilidades que oportunizem a formação inicial e continuada de professores que possuam riqueza de dimensóes que esse processo demanda.

A baixa convivência ao "ar livre" incentiva a dicotômica e moderna distinção homem e natureza, distanciando os docentes de um dos principais meios em que se conjuga a educação ambiental. Essa falta de aproximação, dificulta tanto um pensamento quanto uma prática sistêmica (CAPRA, 2006; LEFF, 2006; 2010), podendo fortalecer ou favorecer no professor uma visão antropocêntrica, disciplinar e fragmentada, pois o meio "natural" fica como algo externo ao saber docente.

Outro elemento que emergiu nos resultados foi a falta de motivação e de formação, problemas identificados por Brancher e Oliveira (2017). Também a rigidez de pensamento, identificada, demonstra a necessidade de mais diálogo entre professores, seja nos cursos, nas salas de aula, ou mesmo consigo. Segundo Carvalho (2008), as formaçốes precisam dialogar com o mundo e com o contexto de vida dos docentes, englobando "[...] suas experiências, seus projetos de vida, suas condiçốes de existência, suas expectativas sociais, sob a pena de serem recebidos como mais uma tarefa entre tantas que tornam o cotidiano do professor um sem-fim de compromissos" (CARVALHO, 2008, p. 60). Dessa forma, fazer sentido e estar interconectada ao mundo cultural e material dos docentes, pode fazer a formação em EA ser mais significativa e significante. 
Os docentes podem assumir-se transformadores e buscar soluções para as problemáticas através da formação inicial e continuada, como um agente aberto ao vir a ser. A falta de desejo e a baixa procura por formação continuada demonstra que ainda há muito a se caminhar. Por outro lado, valorizar os saberes docentes pode potencializar sua vontade de (trans)formar-se. O despreparo pode se transformar na vontade de aperfeiçoar-se (TARDIF, 2012; IMBERNÓN, 2006; 2010; BRANCHER; OLIVEIRA, 2017; SANTOS et al., 2017).

As políticas públicas precisam existir de fato para que se altere o panorama da formação de professores em educação ambiental. Os frágeis e limitados espaços que as políticas ou as instituiçóes abrem para a educação ambiental, cobram ativismo do docente (JATOBÁ et al., 2009), mas o peso não pode ser colocado somente sobre o professor, visto que, ele é um dos agentes envolvidos no aparato educacional, mas não o único. É preciso incluir a comunidade. Conforme afirma Carvalho (2000), é extremamente recomendável que na tarefa de formação de docentes em EA, sejam envolvidas instituiçôes governamentais e não governamentais, pois é "[...] por meio da articulação entre os diferentes níveis do Estado e das instituiçôes da sociedade civil que a complexidade e a riqueza quanto às diferentes dimensóes que esse processo demanda poderão ser consideradas” (p. 60).

Nas Concepçốes propositivas salienta-se a criação de cursos, o uso da sensibilidade, da afetividade e da reflexão, mudanças na legislação, maior autonomia para docentes, maior uso da educação ao ar livre e a necessidade de colaboração para resolução de problemas. Nesta categoria Concepções propositivas elencaram-se sugestôes para a formação de professores em educação ambiental, como cursos e alteraçôes na legislação. Emergiram como necessidades a transformação política, assim como 'elementos que valorizam a afetividade na formação dos docentes em educação ambiental. As propostas, ainda, apontam para a necessidade de colaboração entre professores, atitude que pode ser potencializada se os diferentes agentes e instituiçôes instigarem e abrirem espaços para o protagonismo docente (IMBERNÓN, 2006).

No que tange à Experienciação emergiu uma proposta de modelo de curso, a criação de ferramentas e métodos mistos, assim como a cooperação para inovação, a participação dialógica e a necessidade de maiores diálogos entre professores. Identificaram-se elementos que tratam das intervenções e, também, dos resultados dessas, deixando claro que não há receitas ou modelos aplicáveis a qualquer contexto, como afirmam Imbernón (2006; 2010) e Barcelos (2008), pois muitos projetos lograram sucesso enquanto outros não atingiram seus objetivos. Quando houve cooperação, diálogo e os professores estiveram envolvidos ativamente nos processos de tomada de decisão e nas ações ocorreram resultados profícuos, o que conflui com as propostas de Maturana (1998), Freire (2015) e Imbernón (2006; 2010), que postulam neste sentido.

O panorama obtido, seja nas composiçóes ou nas experiências, reafirma o caráter plural, diverso e amplo das possibilidades formativas de docentes em EA. Embora as possibilidades sejam múltiplas, os desafios também emergem e mostram que é preciso continuar gerando experiências significativas, sem se deixar desanimar por percalços e barreiras. Como afirma Corrêa (2006), a EA é um processo que sofre alterações e, além disso, "[...] trata-se de uma tarefa complexa, imensa e ubíqua, mas não se pode sucumbir às desesperanças; antes investir na utopia do possível, para então planejar e iniciar um caminho em construção (p. 177). Seguir caminhando coloca-se como a melhor forma de se construir o caminho.

\section{CONSIDERAÇÕES FINAIS}

A partir da análise integrativa tornou-se possível mapear e analisar a formação de professores em EA, assim como observar quais foram os principais avanços e desafios pulsantes nos últimos anos. Desafios e potências continuarão existindo, mas ao explorar produções acadêmicas, fica evidente que possibilidades emergentes podem e devem ser trabalhadas, a fim de fazer avançar, tanto na teoria quanto na prática, a formação de professores em Educação Ambiental. 
Como desafios, as análises apontaram as abordagens superficiais, a visão disciplinar, a falta de políticas públicas, os currículos pouco flexíveis, a falta de formação em educação ambiental e de formação continuada (despreparo), a falta de motivação, a rigidez de pensamento, a falta de diálogo entre professores no desenvolvimento de ações, a necessidade de transformação nas práticas, a acomodação e a falta de contato dos professores com a natureza.

Dos resultados da análise, identificam-se como potências, a realização de intervençôes com reflexividade, a exploração de novas metodologias e do uso de tecnologias sociais e de mídia, a ampliação de espaços de atividade incluindo os não formais e atividades ao ar livre, a diversificação de abordagens, a autoformação, a cooperação e suas possibilidades de multi e interdisciplinaridade, a autonomia na tomada de decisões e as atividades que explorem a afetividade, a criatividade e a arte.

As pesquisas ainda tendem a explorar contextos e entendimentos de professores, sugerindo intervenções, ao passo que as práticas intervencionistas ainda logram espaço secundário. Se o objetivo da educação ambiental é fazer com que ela ajude na transformação da realidade, é necessário intervir, refletir e intervir novamente, pois sem ação, apenas diagnosticamos, mas pouco "tratamos” a problemática.

A busca por metodologias inovadoras, abordagens com diversas técnicas e tecnologias demonstram que há um campo amplo a ser explorado nessas searas. Além disso, utilizar outros espaços para além dos formais e institucionais, embora tenha sido uma prática pouco presente nas pesquisas analisadas, aparece como grande potência para a formação de professores em educação ambiental.

Sugere-se que a cooperação, o diálogo, o uso dos meios e a diversificação de abordagens, as quais coloquem os professores como agentes ativos de sua formação, têm muito a oferecer para a educação ambiental. É preciso explorar contextualmente, atuar localmente e buscar impacto globalmente se pretendemos fazer da educação ambiental uma propulsora de mudanças e dos professores, propulsores de mudanças de si, da sociedade e de nossas relaçóes com o meio. É tempo experimentar a integração de saberes e práticas, eis o que a Análise Integrativa torna evidente.

\section{REFERÊNCIAS}

Agrosino, M. Etnografia e observação participante. Porto Alegre: Artmed, 2009.

Barcelos, V. Educação Ambiental: sobre princípios, metodologias e atitudes. Petrópolis, RS: Vozes, 2008.

Brancher, V. R. et al. In: BRANCHER, V. R..; OLIVEIRA, V. F. (Org.). Formação de professores em Tempos de Incerteza: Imaginários, Narrativas e Processos Autoformadores. Jundiaí: Paco Editorial, 2017.

Brancher, V. R.; Oliveira, V. F. (Re)simbolização da docência: entre imaginários e saberes na defesa do protagonismo dos professores. In: Brancher, V. R. (Org.). Formação de professores em Tempos de Incerteza: Imaginários, Narrativas e Processos Autoformadores. Jundiaí: Paco Editorial, 2017

Capra, F. A teia da vida: uma nova compreensão científica dos sistemas vivos. São Paulo: Cultrix, 2006.

Carvalho, L.M. Educação Ambiental e a formação de professores. Brasília: Coordenação Geral de Educação Ambiental, COEA - MEC, 2000, p. 51-58.

Carvalho, I. C. de M. Educą̧ão Ambiental: a formação do sujeito ecológico. 6ạ ed. São Paulo: Cortez, 2012.

Carvalho, I. C. de M. A invenção do sujeito ecológico: identidade e subjetividade na formação dos educadores ambientais. In: Carvalho, I. C. M. Sato, M. Educação Ambiental: pesquisas e desafios. Porto Alegre: ARTMED, 2008.

Cascino, F. Educação ambiental: princípios, história, formação de professores. 3ạ ed. São Paulo: Editora Senac São Paulo, 2003.

Coimbram, J. de Á. A. Considerações sobre a interdisciplinaridade. In: Philippi Jr. A., Tucci, C.E.M., Hogan, D.J., Navegantes, R. (Org.). Interdisciplinaridade em Ciências Ambientais. São Paulo: Signus Editora, 2000 
Diamond, J. M. Colapso: como as sociedades escolhem o fracasso ou o sucesso. 8a ed. Rio de Janeiro: Record, 2012.

Eckert, C.; Rocha, A. L. C. Etnografia: saberes e práticas. In: Pinto, R. J. P.; Guazzelli, C. A. B. Ciências Humanas: pesquisa e método. Porto Alegre: Editora da Universidade, 2008.

Floriani, D. Marcos Conceituais para o Desenvolvimento da Interdisciplinaridade. In: Philippi Jr. A., Tucci, C.E.M., Hogan, D.J., Navegantes, R. (Org.). Interdisciplinaridade em Ciências Ambientais. São Paulo: Signus Editora, 2000.

Freire, P. Pedagogia da autonomia: saberes necessários à prática educativa. 43a ed. São Paulo: Paz e Terra, 2015.

Gaskell, G. Entrevistas individuais e grupais. In: Gaskell, G.; Bauer, M. W. Pesquisa qualitativa com texto, imagem e som - um manual prático. Petrópolis: Vozes, 2002. p. 64-73.

Gil, A. C. Como elaborar projetos de pesquisa. 5a ed. São Paulo: Atlas, 2010.

Godoy, A. Conservar docilidades ou experimentar intensidades In: Preve, A. M. H.; Corrêa G. (Org.). Ambientes da ecologia: perspectivas em política e educação.1aㅡ ed. Santa Maria: Editora da UFSM, 2007. p. 122 - 137.

Gonzaga, A. M. A pesquisa em educação: um desenho metodológico centrado na abordagem qualitativa. In: Pimenta, S. G.; Ghedin, E.; Franco, M. A. S. (Org.). Pesquisa em educação. São Paulo: Ed. Loyola, 2006.

Gouvêa, G. R. R. Rumos da formação de professores para a Educação Ambiental. Educar, Curitiba, n. 27, p. 163-179, 2006. Editora UFPR.

Grün, M. Ética e educação ambiental: A conexão necessária. Campinas, SP: Papirus, 1996.

Guimarães, M. A dimensão ambiental na educação. Campinas, SP: Papirus, 1995.

HOPIA H, LATVALA E, LIIMATAINEN L. Reviewing the methodology of an integrative review. Scand J Caring Sci. 2016 Dec;30(4):662-669. doi: 10.1111/scs.12327. Epub 2016 Apr 14. PMID: 27074869.

Imbernón, F. Formação continuada de professores. Porto Alegre: Artmed, 2010.

Imbernón, F. Formação docente e profissional: formar-se parra a mudança e a incerteza. 6a Ed. São Paulo, Cortez, 2006.

Jatobá, S. U. S. et al. Ecologismo, ambientalismo e ecologia política: diferentes visóes da sustentabilidade e do território. Soc. Estado. 2009, vol. 24, n.1, pp.47-87. ISSN 0102-6992. http://dx.doi.org/10.1590/S0102-69922009000100004.

Lakatos, E. M. Fundamentos da metodologia cientifica. 7a ed. São Paulo: Atlas, 2010.

Leff, E. Discursos sustentáveis. São Paulo: Cortez, 2010.

Leff, E. Epistemologia ambiental. 4ํㅡㄹ. ed. São Paulo: Cortez, 2006.

Leff, E. Interdisciplinaridade e formação ambiental: antecedentes e contribuiçôes da América Latina. In: Philippi Jr. A., Tucci, C.E.M., Hogan, D.J., Navegantes, R. (Org.). Interdisciplinaridade em Ciências Ambientais. São Paulo: Signus Editora, 2000.

Loureiro, F. B. Educação ambiental e movimentos sociais na construção da cidadania ecológica e planetária. In: Loureiro, C. F. B.; Layrargues, P. P.; Castro, R. S. (Org.). Educação ambiental: repensando o espaço da cidadania. São Paulo: Cortez, 2002.

Martín-Barbero, J. Dos meios às mediaçôes: comunicação, cultura e hegemonia. Rio de Janeiro: UFRJ, 1997.

Maturana, H. Emoções e linguagem na educação e na politica. Belo Horizonte: Ed. UFMG, 1998.

Mendes, K. D. S.; Silverira, R. C. C. P.; Galvão, C. M. Revisão integrativa: método de pesquisa para a incorporação de evidências na saúde e na enfermagem. Texto Contexto Enfermagem, Florianópolis, v. 17, n. 4, p. 758-764, out./dez. 2008

Moraes, R. Mergulhos discursivos: análise textual qualitativa entendida como processo integrado de aprender, comunicar e interferir em discursos. In: Freitas, J. V.; Galiazzi, M. C. (Org.). Metodologias Emergentes de Pesquisa em Educação Ambiental. Ijuí: Unijuí, 2007. 216 p.

Morin, E. A cabeça bem-feita: repensar a reforma, reformar o pensamento. 8ㄹ ed. Rio de Janeiro: Bertrand Brasil, 2003. 
Morin, E. Ciência com consciência. 16a ed. Rio de Janeiro: Bertrand Brasil, 2014.

Morin, Edgar. Introdução ao pensamento complexo. Porto Alegre: Ed. Sulina, 2005.

Neuebfeldt, D. J. Educação Ambiental e Educação Física escolar: uma proposta de formação de professores a partir de vivências com a natureza”. 2016. Monografia (Doutorado) - Curso de Ambiente e Desenvolvimento, Universidade do Vale do Taquari - Univates, Lajeado, 22 nov. 2017.

Porto-Gonçalves, C. W. O desafio ambiental. Emir Sader Organizador. $3^{\circ}$ ed. Rio de Janeiro, 2012.

Santos, C. S., et al. As interfaces da docência: olhares, movimentos, horizontes na/com a formação de professores. In: Brancher, V. R.; Oliveira, V. F. (Org.). Formação de professores em Tempos de Incerteza: Imaginários, Narrativas e Processos Autoformadores. Jundiaí: Paco Editorial, 2017.

Severino, A. J. Teoria e Prática Científica. In: Severino, A. J. 23a ed. Metodologia do Trabalho Científico. São Paulo: Cortez, 2007.

Sibilia, P. Redes ou paredes: a escola em tempos de dispersão. Rio de Janeiro: Contraponto, 2012.

Silva, D. J. O Paradigma Transdisciplinar: Uma perspectiva Metodológica para a Pesquisa Ambiental. In: A. Philippi Jr., C.E.M. Tucci, D.J. Hogan, R. Navegantes (Org.). Interdisciplinaridade em Ciências Ambientais. São Paulo: Signus Editora, 2000.

Tristão, M. A educação ambiental na formação de professores: redes de saberes. São Paulo: Annablume, Vitória, Facitec, 2004.

Vergara, S. C. Projetos e relatórios de pesquisa em administração. São Paulo: Atlas, 2005.

WHITTEMORE, R. KNAFL, K. The integrative review: updated methodology. J Adv Nurs. 2005 Dec;52(5):546-53. doi: 10.1111/j.1365-2648.2005.03621.x. PMID: 16268861.

\section{NOTAS}

1 O presente trabalho foi realizado com apoio da Coordenação de Aperfeiçoamento de Pessoal de Nível Superior Brasil (CAPES) - Código de Financiamento 001. Thisstudy was financed in part by the Coordenação de Aperfeiçoamento de Pessoal de Nivel Superior - Brasil (CAPES) -Finance Code 001.

2 Em outro estudo dos pesquisadores se aborda as pesquisas publicadas em Língua Espanhola e em Língua Portuguesa.

\section{Rodrigo Müller Marques}

Titulação: Mestre em Ambiente e Desenvolvimento e Doutorando em Ambiente e Desenvolvimento

Afiliação institucional: Participante como doutorando do projeto de pesquisa Comunicação Educação Ambiental e Intervenções da Universidade do Vale do Taquari - Univates, Lajeado/RS, Brasil.

E-mail: rodrigomarques93@gmail.com

\section{Jane Márcia Mazzarino}

Titulação: Doutora em Ciências da Comunicação pela Universidade do Vale do Rio dos Sinos

Afiliação institucional: Coordenadora do projeto de pesquisa Comunicação Educação Ambiental e Intervenções da Universidade do Vale do Taquari - Univates, Lajeado/RS, Brasil.

E-mail: janemazzarino@univates.br. 
Contato:

Centro de Ensino de Ciências e Matemática de Minas Gerais - CECIMIG

Faculdade de Educação - Universidade Federal de Minas Gerais

revistaepec@gmail.com

Editor responsável:

Guilherme Trópia Barreto Andrade 